Comunicação

[Communication]

\title{
Avaliação da atividade funcional dos neutrófilos sanguíneos em ovelhas primíparas e pluríparas da raça Lacaune
}

[Functional evaluation of blood neutrophils in primiparous and pluriparous Lacaune ewes]

\author{
M. Santos ${ }^{1}$, A.M.M.P.D. Libera ${ }^{2}$, F.N. Souza ${ }^{2}$, S.A. Diniz ${ }^{3}$, L.C.B. Gregolin ${ }^{1}$, \\ L.B.S.B.C. Costa $^{4}$, M.G. Blagitz ${ }^{1}$
}

\author{
${ }^{1}$ Universidade Federal da Fronteira Sul - UFFS - Realeza, PR \\ ${ }^{2}$ Faculdade de Medicina Veterinária e Zootecnia - Universidade de São Paulo - FMVZ-USP - São Paulo, SP \\ ${ }^{3}$ Escola de Veterinária - Universidade Federal de Minas Gerais - EV-UFMG - Belo Horizonte, MG \\ ${ }^{4}$ College of Veterinary Medicine, The Ohio State University (OSU), USA
}

Os neutrófilos são essenciais para a resposta imune inata na defesa do hospedeiro contra patógenos invasores do organismo pelo processo de fagocitose. Durante a fagocitose, os neutrófilos produzem espécies reativas de oxigênio (ERO), as quais são responsáveis pela ação bactericida e consequente eliminação de agentes patogênicos (Souza et al., 2012).

Nesse contexto, é notório que mudanças metabólicas expressivas que ocorrem durante a gestação e a lactação em ruminantes estejam associadas ao comprometimento da resposta imune (Santos et al., 2018). Apesar de as alterações imunológicas em bovinos nesse momento serem bem caracterizadas, poucos estudos avaliaram a resposta imune em ovinos (Sucupira et al., 2019).

Ademais, sabe-se que vacas primíparas apresentam maior capacidade fagocítica e bactericida do que vacas pluríparas (Mehrzad et al., 2009). No entanto, até onde se sabe, não há na literatura estudos que avaliaram diferenças na capacidade fagocítica e bactericida de neutrófilos em ovelhas tanto primíparas quanto pluríparas, apesar de diferenças na susceptibilidade a infecções intramamárias durante o período pósparto, entre essas categorias animais, já terem sido descritas (Takano et al., 2018). Diante do supracitado, o presente estudo teve como objetivo avaliar o metabolismo oxidativo e a fagocitose de neutrófilos sanguíneos de ovelhas primíparas e pluríparas da raça Lacaune pelo teste de tetrazólio nitroazul (NBT), durante os primeiros 30 dias após o parto.

O presente estudo atendeu aos princípios éticos em pesquisa animal e foi aprovado pela Comissão de Ética em Uso de Animais da Faculdade de Medicina Veterinária e Zootecnia da Universidade de São Paulo (protocolo $n^{\circ}$ 23205.001380/2016-74).

Foram coletadas 120 amostras de sangue de 10 ovelhas primíparas (GPR) e 10 ovelhas pluríparas (GPL) provenientes do mesmo rebanho, em seis momentos: no dia do parto (momento 1), um dia após o parto (momento 2), três dias após o parto (momento 3), sete dias após o parto (momento 4), 15 dias após o parto (momento 5), e 30 dias após o parto (momento 6). As amostras de sangue foram coletadas por venopunção da veia jugular de ovelhas, em frascos do tipo Vacutainer ${ }^{\circledR}$ com anticoagulante heparina, para a avaliação do metabolismo oxidativo e da fagocitose de neutrófilos.

No laboratório, a avaliação da atividade funcional dos neutrófilos foi realizada pela técnica de tetrazólio nitroazul (NBT), com kit comercial (cat. n. 0329, Amresco, Solon, EUA), conforme método citoquímico descrito por Park e Good (1970). Foram homogeneizados $50 \mu \mathrm{L}$ de solução de $1,5 \%$ de NBT com $1 \mathrm{~mL}$ de sangue heparinizado, em um tubo de ensaio na técnica 
não estimulada (NBT-NE), e, em outro tubo de ensaio na técnica estimulada (NBT-E), foram homogeneizados $50 \mu \mathrm{L}$ de solução de $1,5 \%$ de NBT com $1 \mathrm{~mL}$ de sangue heparinizado e $10 \mu \mathrm{L}$ de estimulante (Zymosan A de Saccharomyces cerevisiae, cat. n. Z4250, Sigma Aldrich, St. Louis, EUA). Ambos os tubos foram incubados a $37^{\circ} \mathrm{C}$, por 10 minutos, e, em seguida, os esfregaços sanguíneos foram confeccionados em duplicata e corados com corante panóptico rápido. De cada esfregaço sanguíneo corado, foram contados 100 neutrófilos utilizando-se microscópio óptico em objetiva de imersão (100x). Para o NBT-E e o NBT-NE, foram considerados positivos os neutrófilos que reduziram o tetrazólio de nitroazul, ou seja, os neutrófilos que apresentaram grânulos citoplasmáticos de cor violácea ou enegrecida (cristais de formazan), independentemente do número e tamanho das granulações. Na técnica estimulada, os neutrófilos que apresentaram partículas de Zymosan no seu interior foram considerados positivos para a fagocitose.

Os dados foram avaliados quanto à normalidade e à homocedasticidade pelo teste Shapiro-Wilk. Em seguida, aplicou-se o teste ANOVA, seguido pelo teste de Student-Newman-Keuls, para a comparação entre os grupos e os momentos. O valor de $\mathrm{P} \leq 0,05$ foi considerado como significativo.

Tabela 1. Metabolismo oxidativo (redução do tetrazólio de nitroazul) e fagocitose de partículas de Zymosan por neutrófilos sanguíneos de ovelhas primíparas e pluríparas da raça Lacaune

\begin{tabular}{ccccc}
\hline & \multicolumn{2}{c}{ Metabolismo oxidativo } & Fagocitose \\
\hline Grupo & Momento & Basal $(\%)$ & Estimulado $(\%)$ & Zymosan $(\%)$ \\
\hline 1 & 1 & $58,20( \pm 3,13)^{\mathrm{Ba}}$ & $49,90( \pm 2,96)^{\mathrm{Aa}}$ & $52,10( \pm 4,16)^{\mathrm{Ba}}$ \\
1 & 2 & $57,00( \pm 5,69)^{\mathrm{ABa}}$ & $48,30( \pm 3,52)^{\mathrm{Aa}}$ & $56,20( \pm 5,00)^{\mathrm{Ba}}$ \\
1 & 3 & $53,90( \pm 4,58)^{\mathrm{Ca}}$ & $49,20( \pm 1,78)^{\mathrm{Aa}}$ & $51,60( \pm 3,57)^{\mathrm{Ba}}$ \\
1 & 4 & $50,20( \pm 3,68)^{\mathrm{Da}}$ & $52,50( \pm 3,41)^{\mathrm{Aa}}$ & $59,60( \pm 3,08)^{\mathrm{Ba}}$ \\
1 & 5 & $53,10( \pm 2,85)^{\mathrm{Da}}$ & $52,10( \pm 2,97)^{\mathrm{Aa}}$ & $60,10( \pm 3,50)^{\mathrm{Ba}}$ \\
1 & 6 & $56,00( \pm 4,21)^{\mathrm{Ea}}$ & $48,30( \pm 2,80)^{\mathrm{Aa}}$ & $59,70( \pm 3,13)^{\mathrm{Ba}}$ \\
\hline 2 & 1 & $67,50( \pm 4,24)^{\mathrm{BEa}}$ & $45,40( \pm 3,27)^{\mathrm{Aa}}$ & $78,30( \pm 2,88)^{\mathrm{Ab}}$ \\
2 & 2 & $66,30( \pm 3,70)^{\mathrm{BEa}}$ & $48,30( \pm 2,48)^{\mathrm{Aa}}$ & $81,30( \pm 2,32)^{\mathrm{Abc}}$ \\
2 & 3 & $64,20( \pm 2,90)^{\mathrm{BCEa}}$ & $52,70( \pm 3,77)^{\mathrm{Aa}}$ & $85,80( \pm 2,59)^{\mathrm{Abcd}}$ \\
2 & 4 & $69,50( \pm 1,56)^{\mathrm{Aa}}$ & $54,70( \pm 4,23)^{\mathrm{Aa}}$ & $86,50( \pm 2,25)^{\mathrm{Aac}}$ \\
2 & 5 & $67,90( \pm 3,74)^{\mathrm{Ba}}$ & $50,00( \pm 4,31)^{\mathrm{Aa}}$ & $87,50( \pm 1,89)^{\mathrm{Aac}}$ \\
2 & 6 & $64,90( \pm 4,30)^{\mathrm{BCEa}}$ & $50,20( \pm 4,72)^{\mathrm{Aa}}$ & $88,70( \pm 2,41)^{\mathrm{Aad}}$ \\
\hline
\end{tabular}

Resultados expressos em média \pm erro-padrão da média.

Letras maiúsculas indicam diferença estatística $(\mathrm{P} \leq 0,05)$ entre os grupos; letras minúsculas indicam diferença estatística $(\mathrm{P} \leq 0,05)$ entre os momentos dentro do mesmo grupo.

Grupo 1: ovelhas primíparas; grupo 2: ovelhas pluríparas.

Momento 1: dia do parto; momento 2: um dia após o parto; momento 3: três dias após o parto; momento 4: sete dias após o parto; momento 5: 15 dias após o parto; e momento 6: 30 dias após o parto.
Os resultados obtidos estão sumarizados na Tab. 1. Em relação ao metabolismo oxidativo basal (MOB), não foram observadas diferenças na porcentagem de neutrófilos reativos ao NBT entre os momentos tanto das GPR quanto das GPL $(\mathrm{P}<0,05)$. Em relação à diferença entre os grupos no MOB, as GPR no M1 apresentaram menor atividade de neutrófilos que o M4 das GPL. O M3 das GPR apresentou menor atividade de neutrófilos que os momentos 1, 2, 4 e 5 das GPL. Tanto o M4 quanto o M5 das GPR tiveram diferenças estatísticas em relação a todos os momentos das GPL, enquanto o M6 das GPR apresentou diferenças apenas no M4 e no M5 das

O momento e a categoria animal não afetaram o metabolismo oxidativo estimulado (MOE).

A porcentagem de fagocitose de partículas de Zymosan no M1 foi menor que no M4, no M5 e 6 nos animais do GPL; nesse mesmo grupo, por neutrófilos no M2 em relação ao M6 $(\mathrm{P}<0,05)$. Não houve efeito do momento sobre essa variável em animais do GPR. Além disso, verificou-se que a porcentagem de fagocitose de partículas de Zymosan por neutrófilos foi menor nos animais GPR do que em animais do GPL em todos os momentos avaliados. 
Os resultados encontrados no trabalho de Fonteque et al. (2013), realizado com cabras da raça Saanen, todas primíparas, demonstram redução do MOB dos neutrófilos nos primeiros três dias após o parto, diferença não estabelecida em ambos os grupos neste trabalho. Porém, os resultados indicam diferenças entre os grupos, demonstrando maior atividade de neutrófilos reativos ao NBT no GPL.

Diferentemente do presente estudo, Mehrzad et al. (2002), ao compararem vacas primíparas e pluríparas da raça Holandesa, observaram redução expressiva na produção de ERO por neutrófilos avaliados pelo ensaio de quimioluminescência no parto. Porém esses autores observaram que as vacas primíparas restabeleceram a atividade mais rapidamente. Assim, ficou claro, para esses autores, que a produção de ERO foi maior em vacas primíparas do que em pluríparas, corroborando o estudo de Gilbert et al. (1993), o qual apresentou maior produção de ânions superóxidos por neutrófilos pelo ensaio de redução do ferricitocromo c pela superóxido dismutase em vacas primíparas do que em pluríparas. A discrepância desses resultados com o presente estudo leva a refletir sobre o impacto do ensaio utilizado sobre os resultados encontrados, além da extrapolação de informações adquiridas para a espécie ovina, sem considerar a particularidade da espécie. Nesse contexto, Rinaldi et al. (2008), ao avaliarem ensaios que discriminam a produção intracelular ou extracelular de EROS por neutrófilos, observaram que o ensaio de quimioluminescência e a redução do ferricitocromo c avaliam a produção extracelular de neutrófilos, como empregado por Mehrzad et al. (2002) e Gilbert et al. (1993), respectivamente, enquanto as sondas 2',7'- dicloro-hidrofluoresceína diacetato e dihidrorodamina são específicas para mensurar a produção intracelular de ERO.

Assim, embora a produção de ERO seja crucial para a capacidade microbicida de neutrófilos, sabe-se que a produção intracelular de ERO é essencial para garantir a capacidade microbicida de neutrófilos, enquanto a produção extracelular de ERO pode estar associada ao estresse oxidativo. Portanto, ao se extrapolarem esses dados aos achados de Gilbert et al. (1993) e Mehrzad et al. (2002), pode-se dizer que, na verdade, as vacas primíparas estão mais susceptíveis ao estresse oxidativo do que as vacas pluríparas. No presente estudo, ao se utilizar o teste de redução do NBT, teste simples que avalia a produção intracelular de ERO (Miller Jr. e Griendling, 2002), pode-se dizer que foi mensurada a produção intracelular de ERO dos neutrófilos em ovelhas primíparas e pluríparas, o que justifica a divergência entre os resultados encontrados no presente estudo em ovelhas com os descritos na literatura com bovinos. Assim, a interpretação dos resultados de metabolismo oxidativo entre diferentes estudos deve ser cuidadosamente avaliada.

Além disso, em outro estudo realizado por Mehrzad et al. (2009), esses autores avaliaram a porcentagem da fagocitose de neutrófilos entre vacas primíparas e pluríparas no pós-parto. Foi avaliada fagocitose de Staphylococcus aureus das células tanto do sangue quanto do leite, a qual, nas vacas primíparas, foi maior do que nas pluríparas. Isso também contrapõe os resultados de fagocitose deste trabalho, já que as ovelhas pluríparas, em todos os momentos, apresentaram maior porcentagem de neutrófilos em fagocitose do que as primíparas. Essa diminuição da atividade bactericida observada por Mehrzad et al. (2009) torna as vacas pluríparas mais susceptíveis às doenças infecciosas.

Sucupira et al. (2019) realizaram estudo com ovelhas pluríparas no período de transição, por meio da citometria de fluxo. Esses autores avaliaram a intensidade de neutrófilos que fagocitaram Escherichia coli e Staphylococcus aureus no sangue. Apesar de esses autores não terem avaliado a porcentagem de neutrófilos que estavam em fagocitose, eles observaram que as ovelhas pluríparas apresentaram menor intensidade de fagocitose no dia do parto em relação aos demais momentos, indicando que o mesmo afeta negativamente a fagocitose.

No presente estudo, pode-se concluir que os neutrófilos de ovelhas pluríparas são mais eficientes no metabolismo oxidativo e na fagocitose do que os neutrófilos de ovelhas primíparas.

Palavras-chave: ovelha leiteira, período pósparto, metabolismo oxidativo, fagocitose 


\begin{abstract}
This study aimed to evaluate the neutrophil oxidative metabolism and phagocytosis of Zymonsan particles of primiparous and pluriparous Lacaune ewes during the first 30 days after lambing. A total of 20 ewes were evaluated, 10 primiparous (GPR) and 10 pluriparous (GPL). Evaluation of basal oxidative metabolism was performed using the nitroblue tetrazolium (NBT) technique, stimulating neutrophil phagocytosis with Zymosan particles. Blood samples were collected at parturition day (M1) and 1, 3, 7, 15 and 30 days after parturition, corresponding to M2, M3, M4, M5 and M6, respectively. In relation to the groups, GPR presented lower oxidative basal metabolism neutrophils in M1 compared to M4, in M3 with M1, M2, M4 and M5. In M4 and M5 differences were found at all times and in M6 with M4 and M5. Higher percentage of neutrophils than phagocytes were found in M4, M5 and M6 than in M1 and M2 in GPL animals. At all times GPR presented a lower percentage of phagocytosis than GPL. Thus it is concluded that the immune response in pluriparous sheep was more efficient than in primiparous sheep.
\end{abstract}

Keywords: dairy ewe, postpartum period, oxidative metabolism, phagocytosis, parity

\section{AGRADECIMENTOS}

Os autores agradecem ao Conselho Nacional de Desenvolvimento Científico e Tecnológico (CNPq) e à Fundação Araucária, pelo suporte financeiro.

\section{REFERÊNCIAS}

FONTEQUE, J.H; SAITO, M.E; BARIONI, G. et al. Leucograma e metabolismo oxidativo de neutrófilos em cabras da raça Saanen nos períodos de gestação, parto e pós-parto. Pesqui. Vet. Bras., v.33, p.63-70, 2013.

GILBERT, R.O.; GRÖHN, Y.T.; MILLER, P.M.; HOFFMAN, D.J. Effect of parity on periparturient neutrophil function in dairy cows. Vet. Immunol. Immunopathol., v.36, p.75-82, 1993.

MEHRZAD, J.; DUCHATEAU, L.; BURVENICH, C. Phagocytic and bactericidal activity of blood and milk-resident neutrophils against Staphylococcus aureus in primiparous and multiparous cows during early lactation. Vet. Microbiol. v.134, p.106-112, 2009.

MEHRZAD, J.; DUCHATEAU, L.; PYORALAT, S.; BURVENICH, C. Blood and milk neutrophil chemiluminescence and viability in primiparous and pluriparous dairy cows during late pregnancy, around parturition and early lactation. J. D. Sci., v.85, p.3268-3276, 2002.

MILLER JR, F.J.; GRIENDLING, K.K. Functional evaluation of nonphagocytic NAD(P)H oxidases. Methods Enzymol., v.353, p.220-233, 2002.
PARK, B.H.; GOOD, R.A. NBT test stimulated. Lancet, v.1, p.616, 1970.

RINALDI, M.; MORONI, P.; PAAPE, M.J.; BANNERMAN, D.D. Differential alterations in the ability of bovine neutrophils to generate extracellular and intracelular reactive oxygen species during the periparturient period. Vet. J., v.178, p.208-213, 2008.

SANTOS, K.R.; SOUZA, F.N.; BLAGITZ, M.G.; et al. Mastitis in the transition period: identification of potential blood markers. Arq. Bras. Med. Vet. Zootec., v.70, p.1120-1128, 2018.

SOUZA, F.N.; BLAGITZ, M.G.; PENNA, C.F.A.M.; DELLA LIBERA, A.M.M.P. et al. Somatic cell count in small ruminants: friend or foe? Small Ruminant Res., v.107, p.65-75, 2012.

SOUZA, F.N.; RAMOS SANCHEZ, E.M.; HEINEMANN, M.B.; GIDLUND, M.A. et al. The innate immunity in bovine mastitis: the role of pattern recognition receptors. Am. J. Immunol., v.8, p.166-178, 2012.

SUCUPIRA, M.C.A.; NASCIMENTO, P.M.; LIMA, A.S.; GOMES, M.O.S. et al. Parenteral use of ADE vitamins in prepartum and its influence in the metabolic, oxidative, and immunological profiles of sheep during the transition period. Small Ruminant Res., v.170, p.120-124, 2019.

TAKANO, P.V.; SCAPINI, V.A.C.; VALENTINI, T.; GIRARDINI, L.K. et al. Milk cellularity and intramammary infections in primiparous and multiparous Lacaune ewes during early lactation. Small Ruminant Res., v.167, p.117-122, 2018. 